\title{
Simulasi dan Pembuatan Rangkaian Penyearah Gelombang Penuh dengan Trafo Center Tapped dengan Memakai Perangkat Lunak LT SPICE
}

\author{
Fadliondi $^{1}$, Nur Hasanah ${ }^{2}$, Asriyadi $^{3}$ \\ ${ }^{1)}$ Teknik Elektro Universitas Muhammadiyah Jakarta, ${ }^{2)}$ Pendidikan Teknik Informatika Universitas Negeri \\ Yogyakarta, ${ }^{3)}$ Teknik Elektro Politeknik Negeri Sriwijaya \\ 1) Jl. Cempaka Putih Tengah 27 no 47 Jakarta 10510 \\ 1) fadliondi@ftumj.ac.id \\ Abstrak \\ Simulasi dan eksperimen pada rangkaian penyearah gelombang telah dilaksanakan dengan \\ memakai transformator center tapped dan software LTSPICE.dari hasil percobaan dapat dilihat \\ bahwa pada rangkaian tersebut ketika nilai kapasitor yang terpasang secara paralel pada beban \\ ditambah, tegangan riaknya berkurang.
}

\section{PENDAHULUAN}

Rangkaian penyearah gelombang penuh adalah penyearah yang mengonversikan kedua siklus positif dan negative dari sinyal AC menjadi sinyal DC yang berdenyut. Rangkaian penyearah gelombang penuh juga bisa dibuat dengan memakai trafo centre tapped. Penyearah gelombang penuh dipakai untuk merektifikasi keluaran AC dari sebuah lilitan sekunder trafo stepdown 230/12 V [1]. LTSPICE adalah sebuah bahasa simulasi yang kuat dan digunakan untuk mengimplementasikan rangkaian untuk hasil simulasi [2], [3].

\section{METODE}

Alat yang dibutuhkan pada eksperimen ini adalah 2 buah dioda $1 \mathrm{~N} 4002$ atau yang ekuivalen, resistor $10 \mathrm{kohm}$, kapasitor $1 \mathrm{uF}, 2,2 \mathrm{uF}, 4,7 \mathrm{uF}, 10$ $\mathrm{uF}, 22 \mathrm{uF}, 33 \mathrm{uF}, 100 \mathrm{uF}$ dan $220 \mathrm{uF}$, breadboard, kabel jumper male to male secukupnya, 3 buah kabel probe, 1 buah transformator center tapped yang memiliki output dengan amplitudo $5 \mathrm{~V}$ ) dan 1 buah osiloskop. Resistor adalah sebuah komponen listrik 2 terminal yang pasif yang mengimplementasikan hambatan listrik sebagai sebuah elemen rangkaian [4]. Dioda merupakan sebuah komponen pasif yang bisa di conduced dengan tegangan tertentu [5]. Dioda dipakai untuk merektifikasi sinyal [6]. Kapasitor adalah sebuah komponen listrik dua terminal yang pasif yang menyimpan energi listrik di dalam sebuah medan listrik [7]. Tujuan trafo adalah untuk mentransfer energi dari input ke output melalui medan magnet dan jumlah energi yang ditransfer ditentukan oleh suhu, frekuensi dan rapat fluks [8].

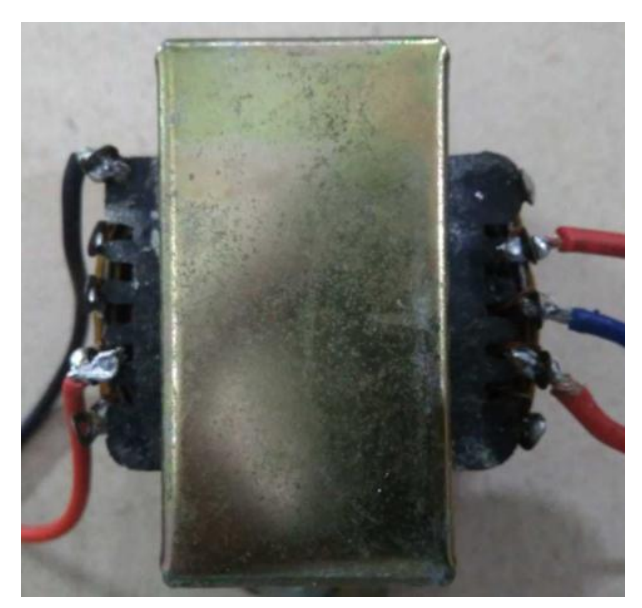

Gambar 1 Trafo.

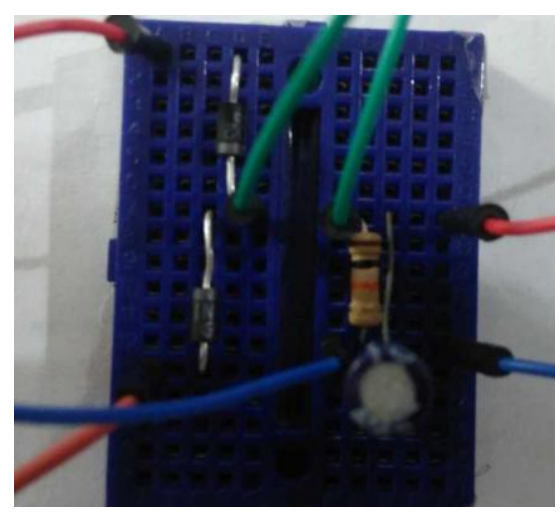

Gambar 2 Rangkaian. 


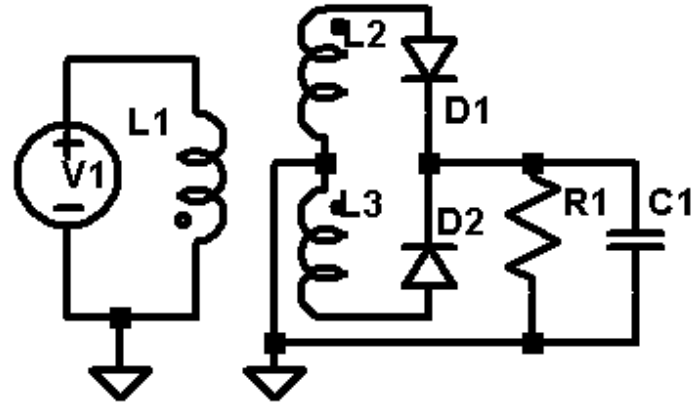

Gambar 3 Rangkaian penyearah gelombang penuh dengan memakai trafo center tapped, 2 buah dioda, 1 buah resistor dan 1 buah kapasitor.

\section{HASIL DAN PEMBAHASAN}
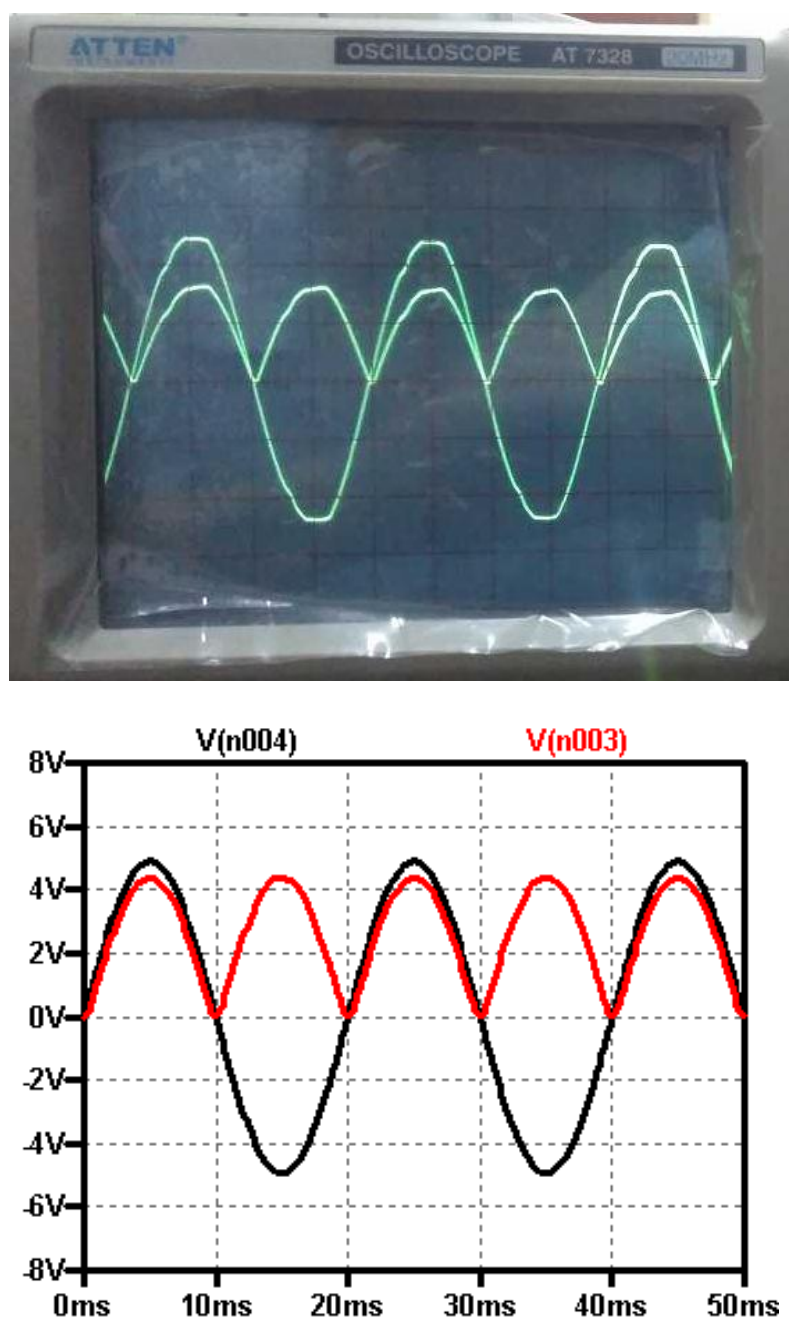

Gambar 4 Hasil eksperimen (kiri) dan simulasi (kanan) dari rangkaian penyearah gelombang penuh dengan memakai 4 buah dioda $1 \mathrm{~N} 4002$, resistor 10 kohm dan tanpa kapasitor.
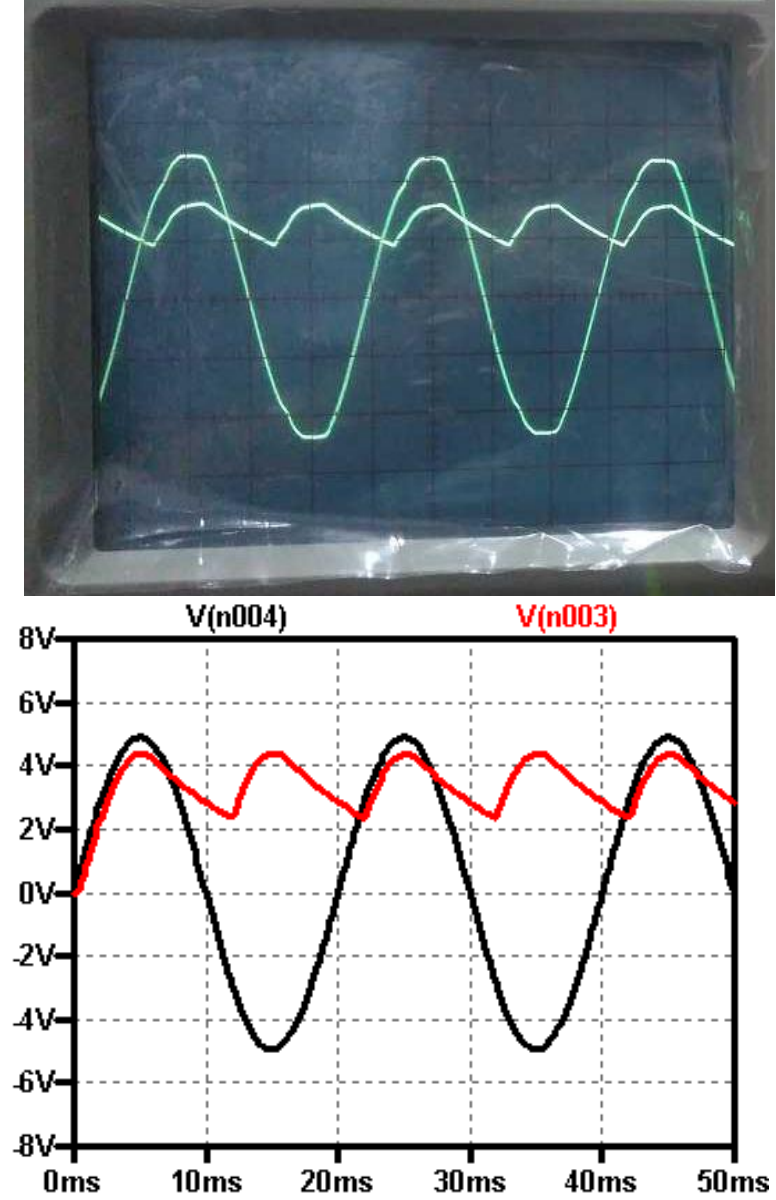

Gambar 5 Hasil eksperimen (kiri) dan simulasi (kanan) dari rangkaian penyearah gelombang penuh dengan memakai trafo center tapped, 2 buah dioda $1 \mathrm{~N} 4002$, resistor $10 \mathrm{kohm}$ dan kapasitor $1 \mathrm{uF}$. 
RESISTOR (elektRonika kEndali telekomunikaSI tenaga liSTrik kOmputeR) Vol. 2 No. 1 e-ISSN : 2621-9700, p-ISSN : 2654-2684
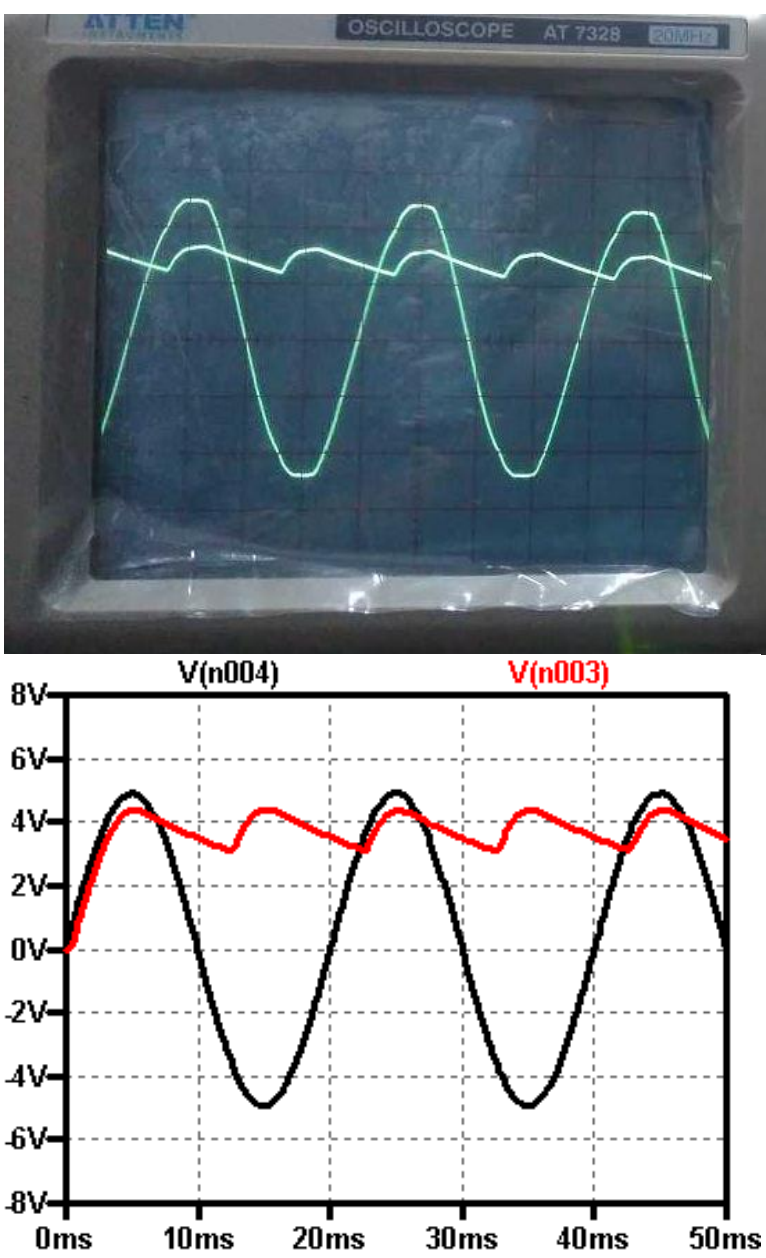

Gambar 6 Hasil eksperimen (kiri) dan simulasi (kanan) dari rangkaian penyearah gelombang penuh dengan memakai trafo center tapped, 2 buah dioda 1N4002, resistor $10 \mathrm{kohm}$ dan kapasitor 2,2 uF.
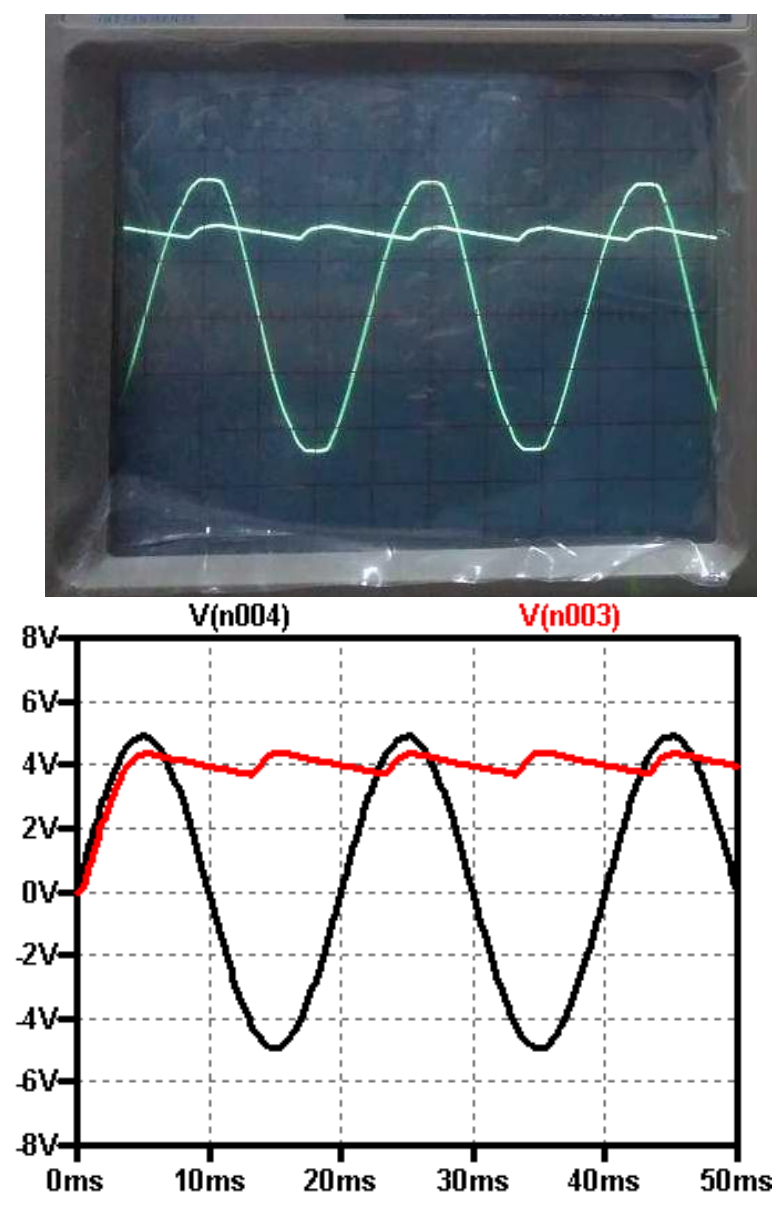

Gambar 7 Hasil eksperimen (kiri) dan simulasi (kanan) dari rangkaian penyearah gelombang penuh dengan memakai trafo center tapped, 2 buah dioda $1 \mathrm{~N} 4002$, resistor $10 \mathrm{kohm}$ dan kapasitor 4,7 uF. 
RESISTOR (elektRonika kEndali telekomunikaSI tenaga liSTrik kOmputeR) Vol. 2 No. 1 e-ISSN : 2621-9700, p-ISSN : 2654-2684
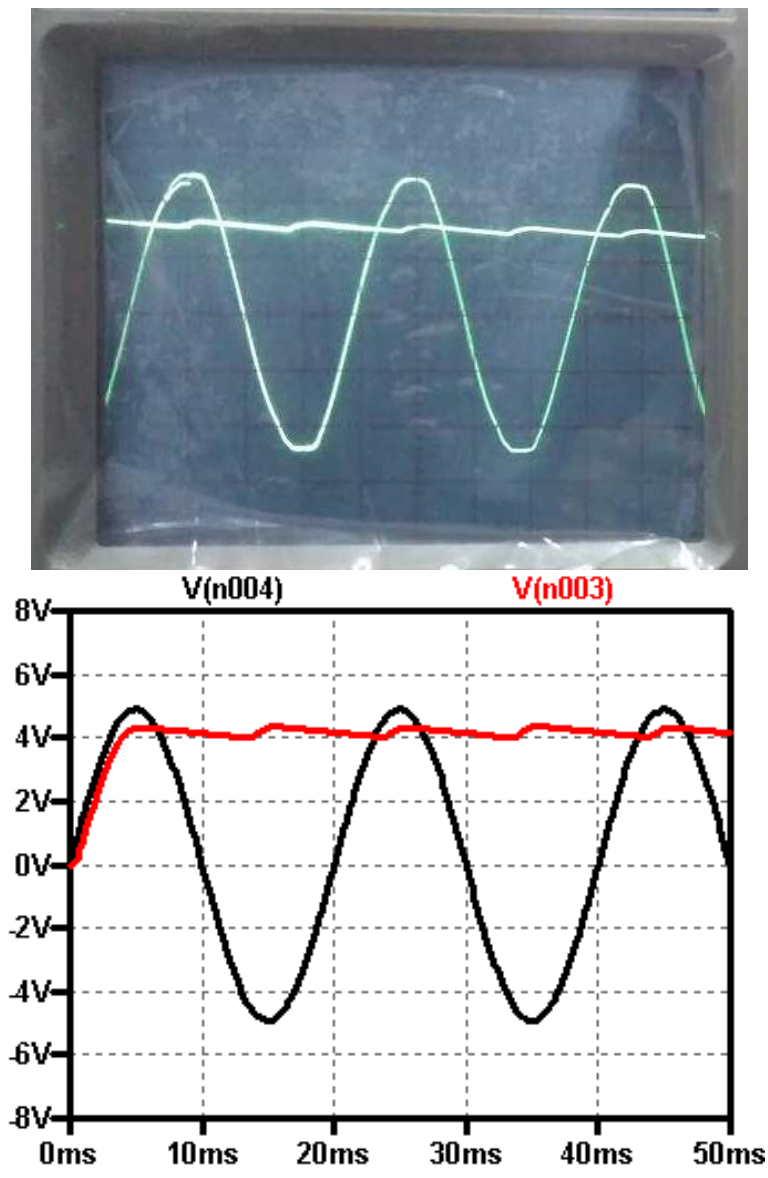

Gambar 8 Hasil eksperimen (kiri) dan simulasi (kanan) dari rangkaian penyearah gelombang penuh dengan memakai trafo center tapped, 2 buah dioda $1 \mathrm{~N} 4002$, resistor $10 \mathrm{kohm}$ dan kapasitor $10 \mathrm{uF}$. 
RESISTOR (elektRonika kEndali telekomunikaSI tenaga liSTrik kOmputeR) Vol. 2 No. 1 e-ISSN : 2621-9700, p-ISSN : 2654-2684
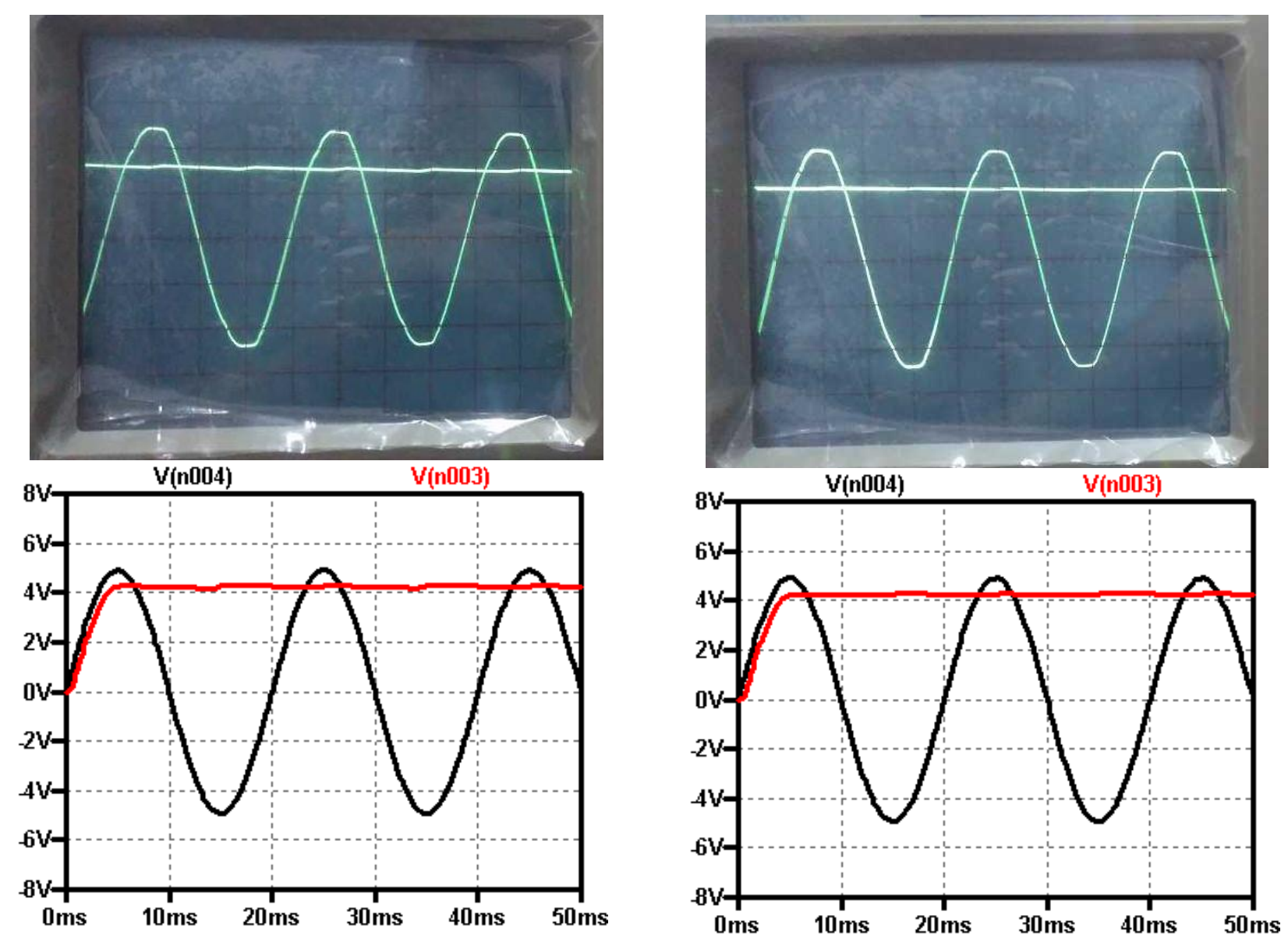

Gambar 10 Hasil eksperimen (kiri) dan simulasi (kanan) dari rangkaian penyearah gelombang penuh dengan memakai trafo center tapped, 2 buah dioda 1N4002, resistor $10 \mathrm{kohm}$ dan kapasitor $33 \mathrm{uF}$.

Gambar 11 Hasil eksperimen (kiri) dan simulasi (kanan) dari rangkaian penyearah gelombang penuh dengan memakai trafo center tapped, 2 buah dioda 1N4002, resistor $10 \mathrm{kohm}$ dan kapasitor $100 \mathrm{uF}$. 
RESISTOR (elektRonika kEndali telekomunikaSI tenaga liSTrik kOmputeR) Vol. 2 No. 1 e-ISSN : 2621-9700, p-ISSN : 2654-2684
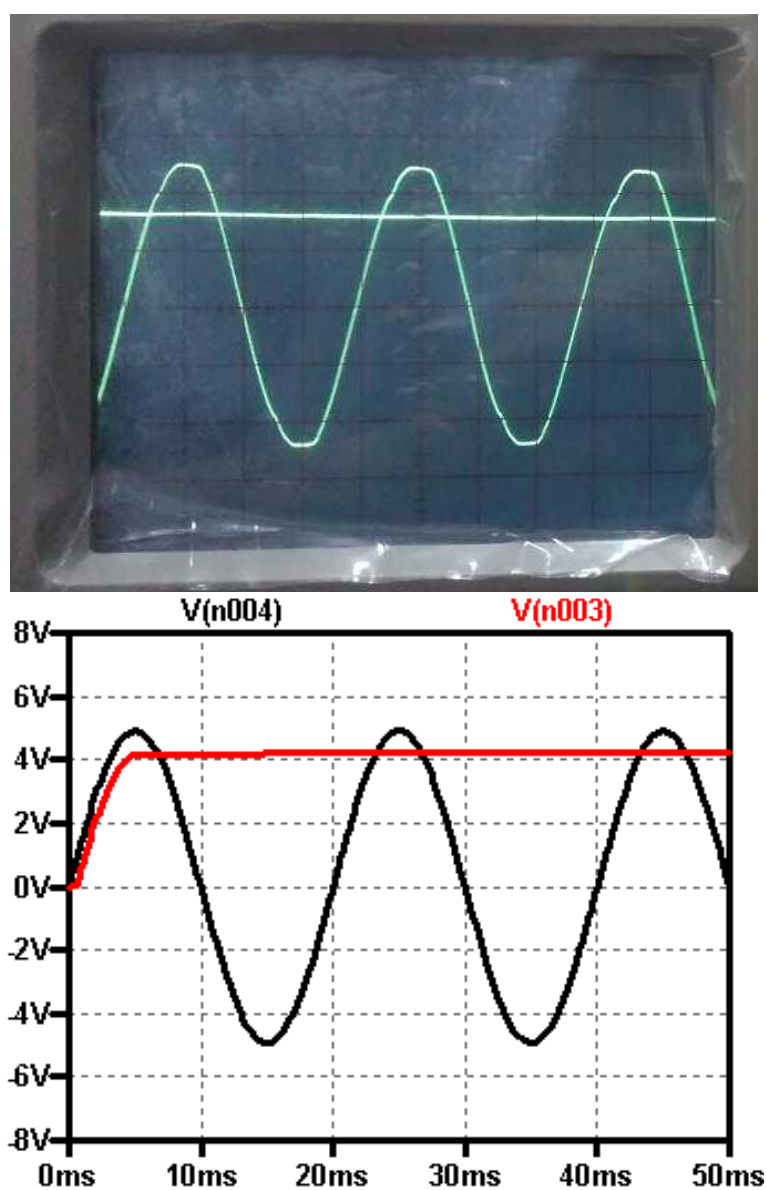

Gambar 12 Hasil eksperimen (kiri) dan simulasi (kanan) dari rangkaian penyearah gelombang penuh dengan memakai trafo center tapped, 2 buah dioda

1N4002, resistor $10 \mathrm{kohm}$ dan kapasitor $220 \mathrm{uF}$.

\section{KESIMPULAN}

Pada penyearah gelombang penuh, tegangan ripple berkurang ketika nilai kapasitor dinaikkan.

\section{UCAPAN TERIMA KASIH}

Penelitian ini adalah salah satu luaran dari hibah Internal Universitas Muhammadiyah Jakarta dengan nomor perjanjian : 31A/LPPM-UMJ/II/2018.

\section{DAFTAR PUSTAKA}

[1] S. V. Satyanarayana and N. Ravi, "SMS BASED WIRE LESS ELECTRONIC NOTICE BOARD USING GSM MOBILE PHONE."

[2] G. Ravikumar and P. Gowri, "Design of a Power Efficient Comparator by Using Domino Logic."

[3] M. G. Giesselmann and V. Roy, "Modeling Power Factor Correction Circuits with LTspice.”
[4] M. S. Hossen, M. T. Islam, and S. Hossain, "DESIGN AND FABRICATION OF A GRAVITY POWERED LIGHT," in International Conference on Mechanical Engineering and Renewable Energy (ICMERE), II, 2015.

[5] J. Liang, L. Jian, M. Chang, and G. Xu, "A compact integrated switched reluctance motor drive with bridgeless PFC converter," in 2013 IEEE Energy Conversion Congress and Exposition, 2013, pp. 4719-4724.

[6] A. Rajawat, K. Suri, and M. Mohta, "Design of an Efficient Rectifier Circuit Based on Karthaus-Fischer Voltage Multiplier for Energy Harvesting," in Intelligent Communication, Control and Devices, Springer, 2018, pp. 913-922.

[7] M. H. A. Bakar, M. N. H. Hadzir, and M. T. Muhamad, "Development of a Capacitor Using a Rubber Based Magneto Rheological Elastomer," in Advanced Engineering for Processes and Technologies, Springer, 2019, pp. 125-134.

[8] W. G. Hurley, W. H. Wolfle, and J. G. Breslin, "Optimized transformer design: Inclusive of high-frequency effects," IEEE Transactions on Power Electronics, vol. 13, no. 4, pp. 651659, 1998. 